Research Article

Open Access

\title{
Hepatotropic, antioxidant and antitoxic action of amaranth oil
}

\author{
Nikolaevsky V.A. ${ }^{1}$, Martirosyan D.M. ${ }^{2}$, Muzalevskaya E.N. ${ }^{1}$, Miroshnichenko L.A. ${ }^{3}$, \\ Zoloedov V.I. ${ }^{4}$
}

${ }^{1}$ Voronezh State University, Voronezh, Russia; ${ }^{2}$ Functional Food Center, Dallas, TX, USA; ${ }^{3}$ OOO «Russkaya Oliva», Voronezh, Russia; ${ }^{4}$ Voronezh State Medical Academy named after N.N. Burdenko, Voronezh, Russia

Corresponding authors: Vladimir I. Zoloedov, MD, Professor, Voronezh State Medical Academy named after N.N. Burdenko, Voronezh, Russia

Submission date: February 12, 2014; Acceptance date: May 7, 2014; Publication date: May 15, 2014

\begin{abstract}
Background: It is our opinion that amaranth seed oil's properties merit further study due to their high quantity of squalene. Squalene has been shown to have antitoxic, antioxidant, and hepatotropic properties. The liver is one of the most important organs in the human body, and as a filtering organ, it is subjected to many toxic compounds and free radicals. Thus, protecting the liver with an antioxidant and antitoxic compound could offer significant benefits.
\end{abstract}

Objective: In the present study we have evaluated the antitoxic, antioxidant, and hepatotropic (hepatoprotective) effects of amaranth oil acquired via a patented pressing method. Rats were treated with amaranth oil, a comparative compound, or a control compound and then subjected to various toxic, oxidizing, and other compounds in order to examine amaranth oil's effects.

Results: Amaranth oil was found to have a positive and dose-dependent effect both in vivo and in vitro. Amaranth oil's hepatoprotective activity was confirmed by both biological and morphological examination. This study suggests that amaranth oil acts to prevent and reduce CT damage in liver tissue. This was especially the case in doses of $300 \mathrm{mg} / \mathrm{kg}$, proved both by normalization of hepatic ferments-markers indexes and morphological examinations.

Conclusion: The amaranth oil acquired via a patented pressing method possesses antitoxic and antioxidant activity. In this connection, the amaranth oil can be recommended for prophylaxis of toxic and drug-induced liver lesions and as a component of the functional food and dietetics of various diseases.

Keywords: antioxidant activity, free-radical oxidation, hypoxia, erythrocytes hemolysis, squalene, amaranth oil, hepatoprotector, hexenalum sleep, toxic hepatitis 


\section{BACKGROUND}

The liver is one of the major organs of the gastrointestinal tract in the human organism. From a functional and morphological perspective, it is highly sensitive to the damaging activity of chemical compounds. All toxic compounds, whether they be products of amino acids metabolism (phenol, cresol, skatole, etc.); products of intestinal micro flora vital activity; or exogenous xenobiotics coming from the gastrointestinal tract, they first enter the liver, which is considered to be a key organ of metabolism. Quite often in a process of xenobiotics biotransformation, intermediate and highly reactive metabolites are formed, which are able to enter in numerous chemical reactions [11, 15].

According to the World Health Organization, data for the last decades all over the world shows a notable amplification of liver disease. More than 2 billion people worldwide suffer from pathology of the hepatobiliary system, making liver disease 100 times more prevalent than HIV. It has been documented that one of the major etiological factors of liver pathology is the presence of toxic lesions of the liver tissue, often due to alcohol and medicine.

The main objective of both the treatment of liver illnesses and that of the complications they cause is the elimination of etiological factors and the main pathogenetic disease mechanisms. The ultimate goal of treatment is to restore full liver function and morphology [10].

In light of the fact that one of the universal mechanisms of cell damage is oxidation of membranous structures mediated by the intensified production of the reactive oxygen species, it is sensible to use antioxidant agents to help treat and prevent liver disease. For this purpose, vitamins $\mathrm{E}, \mathrm{A}$, and $\mathrm{C}$, as well as the antioxidant enzyme of superoxide dismutase, can be applied as hepatoprotectors. This leads to an inhibition of the lipid per oxidation (LP) processes, stabilizing the hepatocyte membranes and accelerating the reparative processes in the liver [1,3]. Along with this, one of the pathogenetic mechanisms of liver damage is ischemia, which can enhance the free-radical oxidation process in hepatocytes [8]. In studying both compounds, which possess hepatotropic properties and which can be used to treat liver disease, it is important to consider compounds which can act both in an antioxidant and antihypoxic manners. It is also especially useful to consider the potential effects of herbal drugs, which can have benefits in both activity latitude and length of application [1].

In our opinion, one important compound to consider is amaranth oil (Amaranth L.), which contains extraordinarily high levels of squalene (to 8\%). This can be compared with olive oil, which only has $0.7 \%$. The main source of squalene at the moment is the livers of abyssal sharks (the content reaches from 60 to 90\%), which produce it as an adaptive response to the hypoxic requirements arising from floating in major depths [5, 12]. Squalene is one of the most powerful protectors against free radicals activity. In addition, it carries out a role in lipid and steroid metabolism and regulation in an organism, as well as regulation of cholesterol and vitamin D metabolism $[2,7]$.

In addition, the composition of amaranth oil includes such antioxidants like vitamins $\mathrm{E}$ and A. Vitamin $\mathrm{E}$ is estimated to have an intensive antioxidant activity in the cell membrane, which can help to stabilize and protect the cell from oxidation damage, aid in immunodefence, act in an anti-carcinogenic manner, and retard aging. In amaranth oil, vitamin $\mathrm{E}$ is present in its most biologically active trienoic form in levels that reach $1 \%$ [2, 
$6,12]$. Vitamin A participates in the oxidation and reduction processes as well as protein synthesis, and it promotes normal metabolism and cell membrane functions [2, 4, 12].

The content of polynonsaturated fatty acids like Omega-3, which act as building materials for cells of the human body, reaches 51\%. Phosphotides (up to 10\%), which consist predominately of phosphatidylcholine (lecithin), are a constituent of cytoplasmic cell membranes, promote structure restoration, substitute defects of the damaged lipid layer in biological membranes, and recover its physicochemical properties [1, 6, 14].

In the present study we have evaluated antitoxic, antioxidant, and hepatotropic (hepatoprotective) effects of amaranth oil acquired by a patented pressing method [16].

\section{MATERIALS AND METHODS}

The experiments were performed on male non-linear white rats $(n=74)$ weighing 180-250 g and male non-linear pubertal mice weighing 18-22 g, according to protocols approved by the "Rules of Work Operation with Experimental Animals" (the appendix to the order of USSR Public Health Ministry, № 755, 12. 08.1977). All animals lived in standard conditions of the vivarium of the Voronezh state medical academy named after by N.N. Burdenko.

As the background for hepatoprotective activity investigation, we first studied the antitoxic and antioxidant activity of amaranth oil.

Using male non-linear pubertal white rats $(n=14, m=220-230 \mathrm{~g})$, we tested the amaranth oil antitoxic activity in the "hexenalum sleep" test. According to the experimental purposes and tasks, all animals were divided into 3 groups: intact $(n=5)$, experimental $(n=4)$, and control $(n=5)$. Rats of the experimental group were injected subcutaneously with amaranth oil with a single dose of $600 \mathrm{mg} / \mathrm{kg}$ (in recalculation on phosphotides), each 24 hours before the Hexenalum introduction. As a comparison, the drug Essentiale (produced by Sanofi-Aventis) was chosen. It contains essential phosphatides derived from soybean oil and is used widely as a reference hepatoprotector. Essentiale officinal solution was given as a single dose each to the control group animals subcutaneously, 24 hours before the Hexenalum introduction (in a dose of $0.085 \mathrm{mg} / \mathrm{kg}$ ). Animals of the intact group received an equivalent quantity of water perorally. Hexenalum test was performed according to a procedure described in the Management on the experimental preclinical research of new pharmacological substances [13] and procedures described by V.V. Gatsura (1974). Hexenalum was introduced in a single dose in the form of a $4.0 \%$ water solution. An intraperitoneal injection was given in a $60 \mathrm{mg} / \mathrm{kg}$ dose, which is equal to $0.35 \mathrm{ml} / 300 \mathrm{~g}$ of a rat body. Doses in recalculation on solution milliliters were counted individually considering animal body mass. As efficiency criterion the duration of sleep invoked by Hexenalum was estimated. The duration of sleep was registered for each animal in group by stop watch.

The drug was determined to be actively antitoxic active if it provided a reduction of sleep duration in comparison with the intact group of animals.

Antioxidant activity was estimated by influence on structurally functional properties of erythrocytes membranes (in vitro) and lifetime of laboratory animals under the acute hypoxia with hypercapnia (in vivo).

In experiments in vitro, a procedure of acid erythrogram recording was used. These studies required blood erythrocytes of 30 pubertal white non-linear male rats weighing 180250 g. Animals were divided on 6 groups ( $n=5$ in each). Animals of the first control group 
received a physiological solution of Sodium chloride. Animals of the second, third, and fourth groups were injected with amaranth oil in doses of $300 \mathrm{mg} / \mathrm{kg}, 600 \mathrm{mg} / \mathrm{kg}$, and 1200 $\mathrm{mg} / \mathrm{kg}$ (in recalculation on phosphotides), respectively. The fifth experimental group was each injected with a drug of comparison (Essentiale) in the form of officinal solution (in a dose of $80 \mathrm{mg} / \mathrm{kg}$ ). The animals of the sixth group received an equivalent quantity of water. Drugs were introduced only once (single-dosing) into the stomach by metal gastric tube one day before the erythrogram registration. To model the liver lesion (acute toxic hepatitis model), an intraperitoneal injection of carbon tetrachloride (CT, CCl4) was performed (in a dose of $0.4 \mathrm{ml} / \mathrm{kg}$, in the form of a $50 \%$ olive oil solution) one hour before the blood sampling (except in control group animals) [13].

Blood was taken through the caudal veins of anesthetized animals by a resection of the tail tip. Blood gravity flow was collected in the tube with $0.1 \mathrm{ml}$ of Heparinum (5000 Units in $1 \mathrm{ml}$ ) per $1-1.5 \mathrm{ml}$ of blood. Erythrocyte suspension was received via 10 minutes of centrifugation at a rate of $3000 \mathrm{rpm}$, and further extraction of supernatant fluid after triply washing under the same conditions. The hemolysis was induced by $0.1 \mathrm{M}$ hydrochloric acid. The kinetics of erythrocytes hemolysis was assessed by the spectrophotometer.

Following parameters were used to characterize the acid erythrocyte resistance: a constant of the hemolysis peak rate ( $\mathrm{K}_{\max }$, relative units.); value $\mathrm{G}_{\mathrm{sph}}$ of erythrocytes (\%) characterizing the relative part of cells in a spherulation stage; $t_{\text {lat }}$ - time reflecting a stage of erythrocytes hemolysis latency (seconds); and $\mathrm{G}_{50}$ - level of $50 \%$ of a hemolysis (\%).

Assessment of oil influence on the laboratory animals' lifetime under acute hypoxia with hypercapnia required 70 non-linear pubertal male mice weighing of 18-22 g. Animals were divided on 7 groups (10 each). The first group was intact. The second, third, and fourth group served as control and each received a single dosing of $\mathrm{L}$ - thyroxin $(0.5 \mathrm{ml})$ in stomach $(5,10$, and $20 \mathrm{mkg}$, respectively) 2 hours before the examination. The fifth, sixth, and seventh group of animals received amaranth oil preliminarily (within 3 days in doses of $20 \mathrm{mg}$ in recalculation on phosphotides) perorally, 3 times a day. On the 4th day, animals of the control and experimental groups (groups №2-7) took $0.5 \mathrm{ml}$ of L-thyroxin perorally (in a dose of 5, 10, and $20 \mathrm{mkg}$, respectively). The bottleneck was pressurized (V.V.Gatsura, 1974). The time from the moment of hermetic sealing of container up to the last appreciable respiratory locomotion was registered.

A logarithmic graphic chart was made on the dependence of surviving duration on the examinee substance dose after the end of experiment.

To test the oil's hepatoprotective activity, a model of experimental toxic hepatitis (ETH) was used. Experiments were performed on 30 white non-linear male rats of the same age in masses ranging 180-250 g preliminarily, fasting during 18-20 h.

Animals were divided on 6 groups ( $n=5$ each). The first group consisted of intact animals, the second was taken as a control and received distilled water. Animals of the third, fourth, and fifth groups were introduced with amaranth oil one day before the ETH modeling in doses of $300 \mathrm{mg} / \mathrm{kg}, 600 \mathrm{mg} / \mathrm{kg}$, and $1200 \mathrm{mg} / \mathrm{kg}$, respectively. Procedures were executed one time via a metal gastric tube. Animals of the sixth group received a drug of comparison, Essentiale, which was introduced in the form of officinal solution into the stomach in a dose of $80 \mathrm{mg} / \mathrm{kg}$ according via a similar regimen. To simulate toxic hepatitis, animals were unitary hypodermically injected with CT in the form of a 50\% solution on peachy oil in a dose of $0.4 \mathrm{ml}$ on $100 \mathrm{~g}$ animal body mass [13]. 
During ETH modeling, the mortality of animals was not observed. The sheme and CT dose used are sufficient for making a valuable biochemical pattern of the liver parenchyma toxic lesion and also give the chance to follow the direction of induced pathological process. Rats were decapitated under chloroformic anesthesia.

Development of ETH was confirmed using biochemical and morphological research techniques. For biochemical spectrophotometric examinations, the serum was used. It was received by centrifugation of whole blood during $15 \mathrm{~min}$ at rate of $3000 \mathrm{rpm}$. For morphological examination, the tissue samples of a hepatic lobe $(3 \times 3 \times 2 \mathrm{~mm})$ were taken and fixed in $10 \%$ neutral formalin solution. Paraffin sections (4-5 microns in thickness) were imbued with hematoxylin and eosine. Filming of tissue specimens was carried out by means of the fixed USB-chamber in a Levenhuk 8 Mpixel microscope.

Data were analyzed using Student's test (with $P<0.05$ as the threshold for significance). All values are expressed as means \pm SD. Statistical software suitable for biology and medicine were used for calculations.

\section{RESULTS}

The obtained results show that the mean duration of hexenalum sleep in animals of the intact group was 56.6 \pm 12.6 minutes (Table 1). The drug of comparison, Essentiale, provided a considerably significant reduction of sleep duration of $45.6 \%$ compared with intact group. In addition to that, under the influence of amaranth oil, the duration of hexenalum sleep decreased to $32.0 \%$ compared with intact group. Thus differences with Essentiale efficiency were $13.6 \%$.

Table 1. Duration of hexenalum sleep in experimental animals after amaranth oil application

\begin{tabular}{lccc}
\hline Index & $\begin{array}{c}\text { Intact group } \\
(\mathrm{n}=5)\end{array}$ & $\begin{array}{l}\text { Experimental } \\
\text { group }(\mathrm{n}=4)\end{array}$ & $\begin{array}{c}\text { Control group } \\
(\mathrm{n}=5)\end{array}$ \\
\hline $\begin{array}{l}\text { Duration of sleep, } \\
\text { minutes }\end{array}$ & $56,6 \pm 12.6$ & $38.5 \pm 5.0$ & $30.8 \pm 6.6^{*}$ \\
$\begin{array}{l}\text { Difference with intact } \\
\text { group, } \%\end{array}$ & - & $32.0 \%$ & $45.6 \%$ \\
\hline Note: $* \mathrm{p} \leq 0.05$. & & &
\end{tabular}

Effects of amaranth oil influences on indexes of acid erythrograms are shown in table 2.

Analysis of acid hemolysis peak rate constant value $\left(\mathrm{K}_{\max }\right)$, which characterizes a part of erythrocytes population that simultaneously enters into a stage of the hemolysis proper, has shown that unitary intraperitoneal CT introduction in a dose of $0.4 \mathrm{ml} / \mathrm{kg} 1$ hour before the erythrogram recording was accompanied by a reliable augmentation of hemolysis rate among the erythrocytes of average-resistant population by $40.3 \%$ compared to the control group. The rate of erythrocyte hemolysis in the basic average-resistant population at preliminary amaranth oil introduction in doses of $300 \mathrm{mg} / \mathrm{kg}, 600 \mathrm{mg} / \mathrm{kg}$, and $1200 \mathrm{mg} / \mathrm{kg}$, and Essentiale in a dose of $80 \mathrm{mg} / \mathrm{kg}$ did not differ from control indexes significantly. However, it is necessary to notice that amaranth oil introduction on average promoted the $\mathrm{K}_{\max }$ reduction concerning control on $23.1 \%$, $9.0 \%$, and $23.8 \%$, respectively. In case of Essentiale application, the erythrocytes simultaneously entering into a stage of hemolysis 
proper was a little higher (on 1.9\%) compared with erythrocytes of animals in the group that did not receive the substance explored.

Table 2. Changes of erythrocytes acid hemolysis indexes in acute toxic hepatitis model under amaranth oil application

\begin{tabular}{lllll}
\hline \multicolumn{1}{c}{ Name } & $\mathrm{K}_{\max }$, relative units & $\mathrm{G}_{\mathrm{sph}}, \%$ & $\mathrm{t}_{\mathrm{lat}}, \mathrm{sec}$ & $\mathrm{G}_{50} \%$ \\
\hline $\begin{array}{l}\text { Control, } 0,9 \% \\
\text { NaCl solution }\end{array}$ & $5.78 \pm 0.93$ & $-2.60 \pm 1.3$ & $125.0 \pm 45.3$ & $256.70 \pm 37.9$ \\
$\begin{array}{l}\text { Amaranth oil in } \\
\text { a dose of } 300\end{array}$ & $4.45 \pm 0.23^{* *}$ & $-1.25 \pm 0.95^{*}$ & $65.0 \pm 31.2^{*}$ & $235.0 \pm 8.7^{*}$ \\
mg/kg & & & \\
$\begin{array}{l}\text { Amaranth oil in } \\
\text { a dose of } 600\end{array}$ & $5.26 \pm 0.97$ & $-1.20 \pm 1.22^{*}$ & $105.0 \pm 30.0^{* *}$ & $246.70 \pm 15.3^{* *}$ \\
mg/kg & & & \\
$\begin{array}{l}\text { Amaranth oil in } \\
\text { a dose of } 1200\end{array}$ & $4.40 \pm 0.71 * *$ & $-2.65 \pm 0.3^{* *}$ & $105.0 \pm 21.2^{* *}$ & $230.0 \pm 40.0^{*}$ \\
mg/kg & & & \\
$\begin{array}{l}\text { Essentiale in a } \\
\text { dose of } 80\end{array}$ & $5.89 \pm 0.37 * *$ & $-0.48 \pm 1.1^{* *}$ & $80.0 \pm 48.2^{*}$ & $228.3 \pm 2.9^{*}$ \\
mg/kg & & & \\
CT, CCl ${ }_{4}$ & $8.11 \pm 0.0005^{*}$ & $-0.45 \pm 0.096^{*}$ & $50.0 \pm 17.3^{* *}$ & $205.0 \pm 8.7^{*}$ \\
\hline
\end{tabular}

Note: $*-\mathrm{p} \leq 0.01 ; * *-\mathrm{p} \leq 0.05$.

Value of $\mathrm{G}_{\mathrm{sph}}$ index reflecting the relative part of spherocytes, at amaranth oil introduction in doses of $300 \mathrm{mg} / \mathrm{kg}, 600 \mathrm{mg} / \mathrm{kg}$, and $1200 \mathrm{mg} / \mathrm{kg}$, did not differ from the control level reliably. However, in doses of $300 \mathrm{mg} / \mathrm{kg}$ and $600 \mathrm{mg} / \mathrm{kg}$, the part of spherocytes on average values was half as much as the control. In a dose of $1200 \mathrm{mg} / \mathrm{kg}$, it was almost peer to intact level. After Essentiale introduction in a dose of $80 \mathrm{mg} / \mathrm{kg}$, the tendency to $\mathrm{G}_{\mathrm{sph}}$ reduction was expressed more to what the reduction of part of erythrocytes simultaneously being in a spherocytosis stage on $81.5 \%$ compared control. After CT introduction, $\mathrm{G}_{\mathrm{sph}}$ rate was significantly below the control level (on $82.7 \%, \mathrm{p}<0.05$ ). From this fact we considered that preliminary introduction of amaranth oil and Essentiale retards the stage of the hemolysis development and approximates it to the indexes of the control group $_{\text {lat }}$ of acid hemolysis, reflecting the hemolysis latency stage duration, after intraperitoneal introduction of $\mathrm{CT}$ in a dose of $0.4 \mathrm{ml} / \mathrm{kg}$. It was accompanied by the shortening of hemolysis latent time by $60 \%$ compared to the control group. $\mathrm{T}_{\text {lat }}$ lead-acid hemolysis with the use of amaranth oil in doses of $300 \mathrm{mg} / \mathrm{kg}, 600 \mathrm{mg} / \mathrm{kg}, 1200 \mathrm{mg} / \mathrm{kg}$, and Essentiale in a dose of $80 \mathrm{mg} / \mathrm{kg}$ reliably did not differ from the control.

The analysis of time of $50 \%$ of hemolysis occurrence $\left(\mathrm{G}_{50}, \%\right)$ shows that $\mathrm{CT}$ introduction invoked $\mathrm{G}_{50}$ reduction on $20.1 \%$ compared with the control. The amaranth oil and Essentiale retarded development of erythrocyte hemolysis of the basic average-resistant population concerning indexes of animals with $\mathrm{CCl}_{4}$-invoked hepatitis. It has found the reflectance that at preliminary intragastric amaranth oil introduction in doses of $300 \mathrm{mg} / \mathrm{kg}$, 
$600 \mathrm{mg} / \mathrm{kg}$, and $1200 \mathrm{mg} / \mathrm{kg}$ and Essentiale in a dose of $80 \mathrm{mg} / \mathrm{kg}$ before CT application the studied index value reliably did not differ from those in control group.

The analysis of antioxidant activity investigation results on the hypoxia model testified that L-thyroxin in doses of 5, 10, and $20 \mathrm{mkg}$ invoked reduction of lifetime in control group of rats compared intact group by $21.5 \%, 31.4 \%$, and $34.5 \%$, respectively ( $p<0,05)$. Along with this, the preliminary amaranth oil administration in a dose of $20 \mathrm{mg}$ (perorally during 3 days) prolonged the lifetime in experimental group in relation to the control by $9.7 \%$ and $14.7 \%$, respectively (at $\mathrm{p}<0.05$ ) on the background of L-thyroxin - invoked hypoxia (Table $3)$.

Table 3. Degree of experimental animals' resistance to hypoxia with hypercapnia with amaranth oil application

\begin{tabular}{lccc}
\hline Group of animals & $\begin{array}{c}\text { Time of animals } \\
\text { death, minutes } \\
\mathrm{M} \pm \mathrm{m}\end{array}$ & $\begin{array}{c}\text { Reduction of animals } \\
\text { lifetime, \% }\end{array}$ \\
& $131.70 \pm 15.5$ & $\begin{array}{c}\text { Compared } \\
\text { intact group }\end{array}$ & $\begin{array}{c}\text { Compared } \\
\text { control group }\end{array}$ \\
\hline Intact group & $103.40 \pm 5.6$ & 78.5 & - \\
L-thyroxin, $5 \mathrm{mkg}$ & $90.40 \pm 6.68$ & 68.6 & - \\
L-thyroxin, $10 \mathrm{mkg}$ & $86.20 \pm 8.04$ & 65.5 & - \\
L- thyroxin, $20 \mathrm{mkg}$ & Peroral introduction of amaranth oil & - \\
\hline L- thyroxin, $5 \mathrm{mkg}$ & $113.50 \pm 3.5$ & 86.2 & 109.7 \\
L- thyroxin, $10 \mathrm{mkg}$ & $103.70 \pm 6.7$ & 78.7 & 114.7 \\
L- thyroxin, $20 \mathrm{mkg}$ & $84.50 \pm 5.1$ & 64.2 & - \\
\hline
\end{tabular}

Hepatoprotective activity examination after unitary introduction of CT in experimental animals showed development of toxic liver lesions. This was proved by the rising of alanin aminotranspherases (AlAT) and aspartate aminotransferases (AsAT), which are estimated to be the ferments-markers of hepatic cytolysis in relation to datum level on $143 \%$ and $83.5 \%$ ( $p<0.05$ ), respectively. Likewise the increasing of total bilinubin level on 59.2\% was recorded in blood serum. It was estimated as signs of erythrocytolysis and haemoglobin destruction or disturbance in system of conjugated bilirubin transmission from a hepatic cell into bile.

Along with this, liver toxic lesion development was confirmed by the augmentation of whole hexoses by $19.46 \%$ (that specifies on inflammation development); the reduction of free SH-groups by $9.3 \%$ (obviously bound to depression of peroxidases activity); and finally rise of malonic dialdehyde concentration compared initial quantity by $25 \%$, which shows activation of lipid peroxide oxidation and degradation of polynonsaturated fats by the reactive oxygen spices.

Unitar Essentiale introduction in a dose of $80 \mathrm{mg} / \mathrm{kg}$ invoked in rats the reduction of AsAT and AlAT activity almost to a level in the control group (by $64.5 \%$ and $52.2 \%$, respectively); and augmentation of total bilirubin in blood serum by $13 \%$ compared with the control and reduction of whole hexoses by $22.5 \%$.

Unitary introduction of amaranth oil in doses of $300 \mathrm{mg} / \mathrm{kg}, 600 \mathrm{mg} / \mathrm{kg}$, and $1200 \mathrm{mg} / \mathrm{kg}$ against the background of ETH decreased AlAT activity in relation to control on $18 \%, 44.7 \%$, and $68.7 \%$, respectively; suppressed AsAT activity by $19.3 \%$ (in the dose of $600 \mathrm{mg} / \mathrm{kg}$ ) and $35.5 \%$ (in the dose of $1200 \mathrm{mg} / \mathrm{kg}$ ); reduced 
concentration of whole hexoses by $11.8 \%, 24.7 \%$, and 19\%, respectively. Dynamics of biochemical indexes under the ETH are presented in Table 4.

Table 4: Change of biochemical indexes in rat blood serum under the experimental toxic hepatitis on the background of amaranth oil application

\begin{tabular}{|c|c|c|c|c|c|c|}
\hline \multicolumn{7}{|c|}{ Blood serum } \\
\hline $\begin{array}{c}\text { Malonic } \\
\text { dialdehyd, } \\
\mathrm{mcM} / \mathrm{l}\end{array}$ & $\begin{array}{c}\text { AsAT, } \\
\text { mkKAT/l }\end{array}$ & $\begin{array}{c}\text { AlAT, } \\
\text { mkKAT/l }\end{array}$ & $\begin{array}{c}\text { Coefficient } \\
\text { AsAT / } \\
\text { AlAT }\end{array}$ & $\begin{array}{c}\text { Total bilinubin, } \\
\text { mcM/l }\end{array}$ & $\begin{array}{c}\text { Whole } \\
\text { hexoses } \\
(\mathrm{g} / \mathrm{l})\end{array}$ & $\begin{array}{c}\text { Free SH-groups, } \\
\mathrm{mg} \%\end{array}$ \\
\hline \multicolumn{7}{|c|}{ Intact group } \\
\hline $2.0 \pm 0.6$ & $0.51 \pm 0.2$ & $0.73 \pm 0.2$ & -1.43 & $2.16 \pm 0.75$ & $1.49 \pm 0.16$ & $134.72 \pm 4.61$ \\
\hline \multicolumn{7}{|c|}{ Control group (toxic hepatitis model) } \\
\hline $2.5 \pm 0.04$ & $1.24 \pm 0.23$ & $1.34 \pm 0.44$ & -1.08 & $3.44 \pm 1.7$ & $1.78 \pm 0.05$ & $122.15 \pm 1.73$ \\
\hline \multicolumn{7}{|c|}{ Essentiale $0.085 \mathrm{mg} / \mathrm{kg}$} \\
\hline $2.0 \pm 0.01 *$ & $0.8 \pm 0.2 *$ & $0.7 \pm 0.17 * *$ & 1.14 & $3.89 \pm 1.3$ & $1.38 \pm 0.03^{*}$ & $134.21 \pm 5.33^{*}$ \\
\hline \multicolumn{7}{|c|}{ Amaranth oil, $300 \mathrm{mg} / \mathrm{kg}$} \\
\hline $2.1 \pm 0.02$ & $1.25 \pm 0.23$ & $1.1 \pm 0.21 *$ & 1.16 & $5.48 \pm 2.04 * *$ & $1.57 \pm 0.18$ & $130.10 \pm 8.8 *$ \\
\hline \multicolumn{7}{|c|}{ Amaranth oil, $600 \mathrm{mg} / \mathrm{kg}$} \\
\hline $1.5 \pm 0.02 * *$ & $1.0 \pm 0.1 *$ & $0.74 \pm 0.08 *$ & 1.38 & $4.76 \pm 1.05 * *$ & $1.34 \pm 0.34 * *$ & $134.79 \pm 5.74 *$ \\
\hline \multicolumn{7}{|c|}{ Amaranth oil, $1200 \mathrm{mg} / \mathrm{kg}$} \\
\hline $1.4 \pm 0.02 * *$ & $0.8 \pm 0.2 *$ & $0.42 \pm 0.2 * *$ & 2.09 & $4.76 \pm 1.8 *$ & $1.44 \pm 0.17 *$ & $136.61 \pm 3.16^{* *}$ \\
\hline
\end{tabular}

Note: $*-\mathrm{p}<0.05 ; * *-\mathrm{p}<0.01$

In a morphological pattern in all areas of liver tissue lobules, lymphohistiocytic infiltration was revealed except the expressed fatty degeneration of liver.

The portal tract veins hyperemia with leukostasis in it, as well as reduction of glycogen level, were noted.

At an assessment of the structural organization of the livers of the intact group of rats, it was established that the functional activity of the livers of those rats was in limens of the physiological norm, the architectonics and structure of hepatic lobules were without visible changes, changes in interlobular connective tissue were absent (figure 1 a), and the lobule girder structure was of the norm (figure $1 \mathrm{c}$ ). In the perivascular region, individual centrolobular hepatocytes were hypertrophied and extensive vacuolation of liver cells was observed around the central vein, as well as on the periphery. Individual hepatocytes were in a karyopyknosis and karyolysis state. Close-grained fatty degeneration was noted. The 
cytoplasma was light and foamy. The central vein contains inappreciable quantities of blood corpuscles (figure $1 \mathrm{~d}$ ). Centrolobular localisation of damages (figure $1 \mathrm{~b}, \mathrm{c}$ ) prevails.

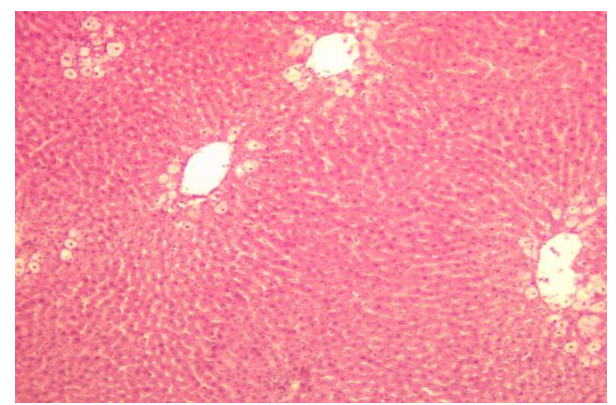

a

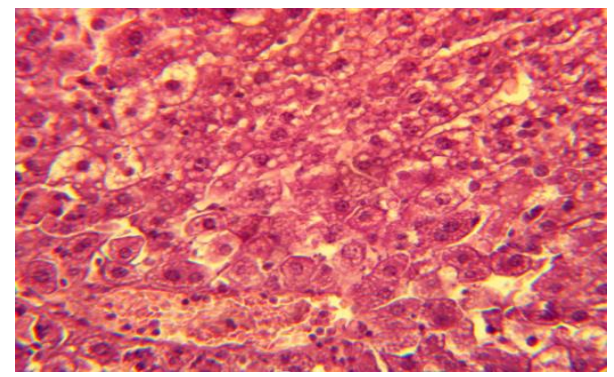

C

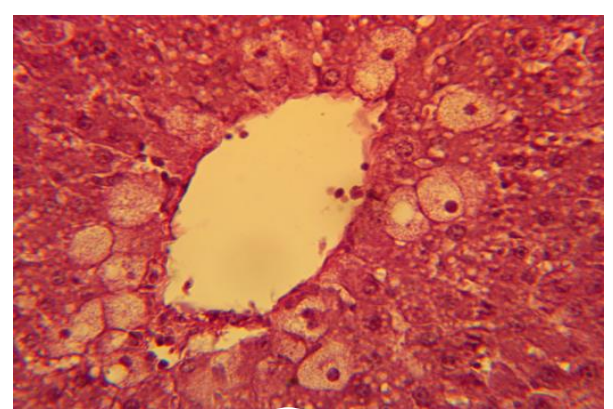

$\mathrm{h}$

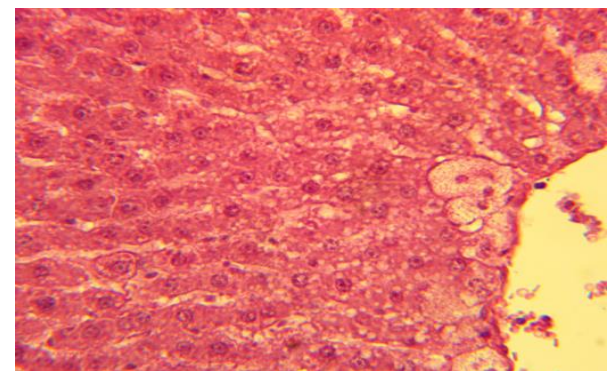

d

Figure 1. The histologic specimen of a rat liver of intact group. Colorated with hematoxylin-eosine. Augmentation: $\mathrm{a}-\times 10 ; \mathrm{b}, \mathrm{c}, \mathrm{d},-\times 40$

Upon microscopic examination of histologic sections of rats' liver in the control group (toxic hepatitis model), the de-condensation of the venous blood vessel walls and the strong cytoplasma clarification around the central vein were observed (Figure $2 a, b$ ), and the blood vessel intima had grown coarse (Figure 2).

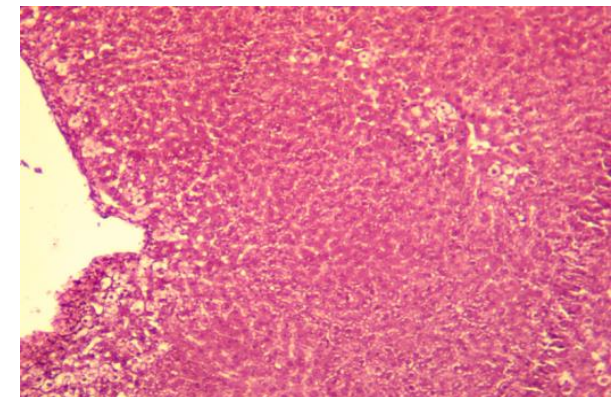

a

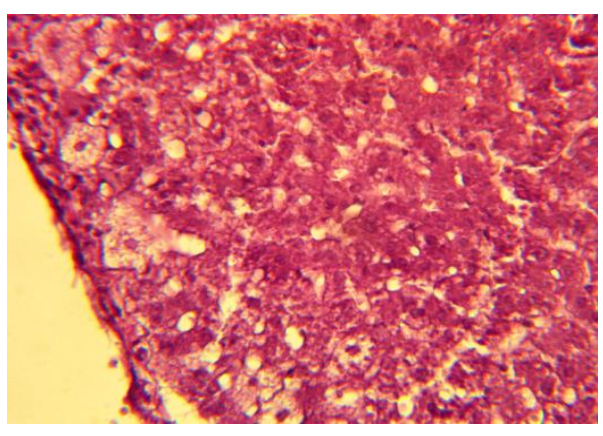

c

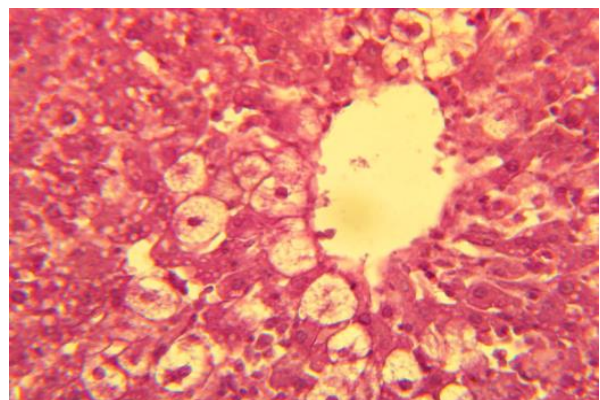

b

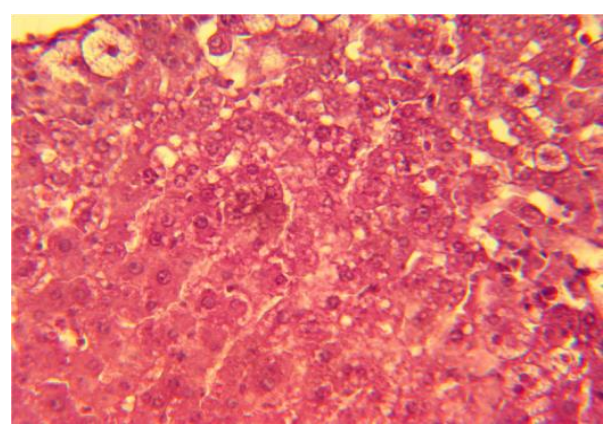

d

Figure 2. The histologic specimen of a rat liver of control group (ETH). Colorated with hematoxylin-eosine. Augmentation: $\mathrm{a}-\times 10$; b, c, d $-\times 40$. 
Loss of the girder structure of hepatic lobules, a balloon dystrophia of cells, and a karyolysis and a karyopyknosis of hepatocytes around the central vein were registered. There were also necrobiotic fields. Individual hepatocytes were strongly vacuolated with nucleus reduction (Figure 2 a-d). Also, disturbances were observed in the field of the central vein and on peripheric fields. The character of the established hepatic tissue structure disturbances and rising of ferments-markers of hepatic cytolysis activity (ALAT and ASAT) corresponded to the changes descending at toxic hepatitis development.

Preliminary Essentiale introduction in a dose of $80 \mathrm{mg} / \mathrm{kg}$ before CT introduction testifies to regenerative activity in the field of the central vein, which is proved by presence of the binuclear and hypertrophied hepatocytes on sections. However, the maintenance of vacuolated hepatocytes on the periphery was noted (Figure $3 \mathrm{c}, \mathrm{d}$ ). Both the architectonics of hepatic lobules and the structure of lobules were without visible changes. There was insignificant de-condensation of interlobular connective tissue. The girder structure of a lobule was expressed weakly (Figure 3 a). The presence of a balloon dystrophia and traces of necrotic changes with centrolobular localization (Figure $3 \mathrm{~b}$ ) were registered. The central vein contained the inappreciable blood corpuscle quantities.

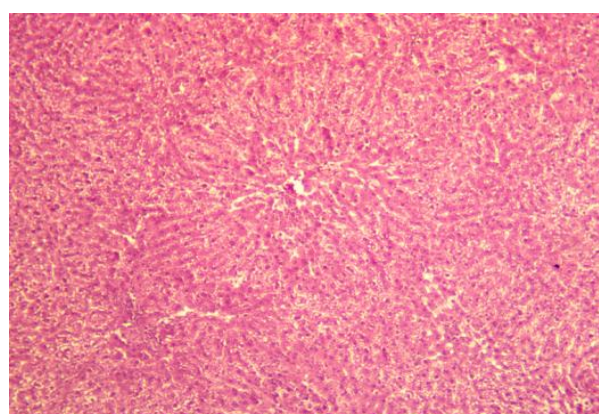

a

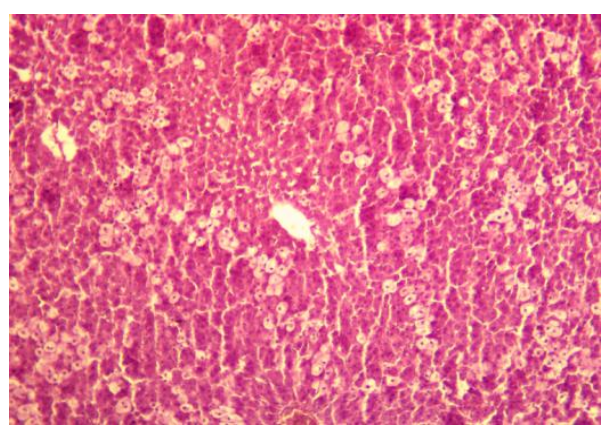

c

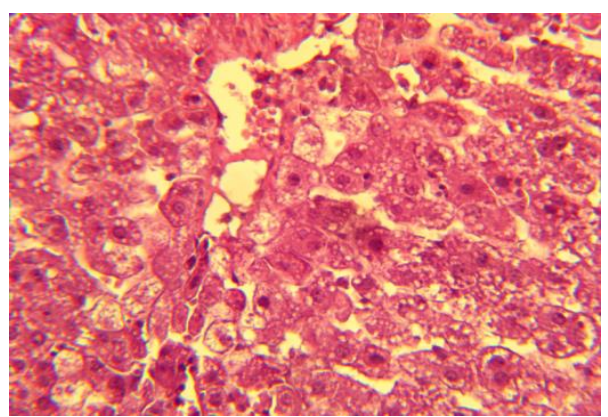

b

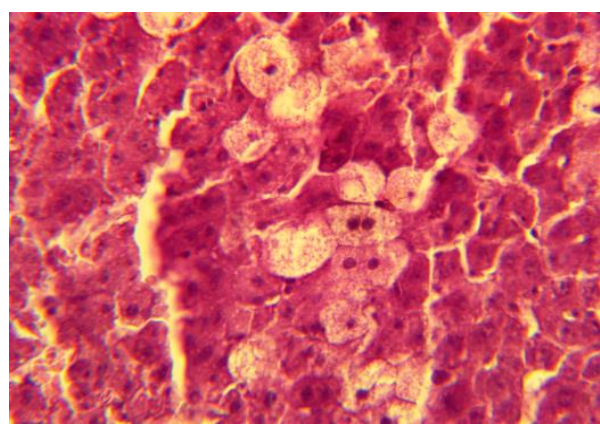

d

Figure 3. The histologic specimen of a rat liver with ETH under Essentiale application in dose of $80 \mathrm{mg} / \mathrm{kg}$. Colorated with hematoxylin-eosine. Augmentation: a, c $-\times 10 ; \mathrm{b}, \mathrm{d}-\times 40$.

The amaranth oil application in a dose of $300 \mathrm{mg} / \mathrm{kg}$ normalized the structural organization of a liver, as well as prevented signs of necrosis, dystrophia, inflammatory responses, and any other damages. Architectonics of hepatic lobules were normal as structure of lobules and changes of interlobular connective tissue were absent. Individual vacuolated hepatocytes and fatty incorporations (Figure 4 a) remained. The expressed signs of regeneration activity confirmed by diffusely located functionally active hepatocytes and appreciable augmentation of binuclear cells (Figure $3 \mathrm{~b}$ ) were observed. In the livers of the animals, receiving amaranth oil preliminary in a dose of $600 \mathrm{mg} / \mathrm{kg}$ caused similar changes 
at morphological examination of microscopic sections. However in this group the individual blood corpuscles in the central vein were present (Figure $4 \mathrm{c}, \mathrm{d}$ ).

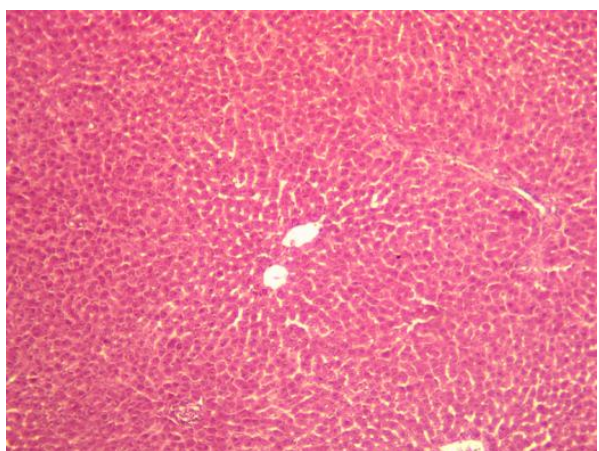

a

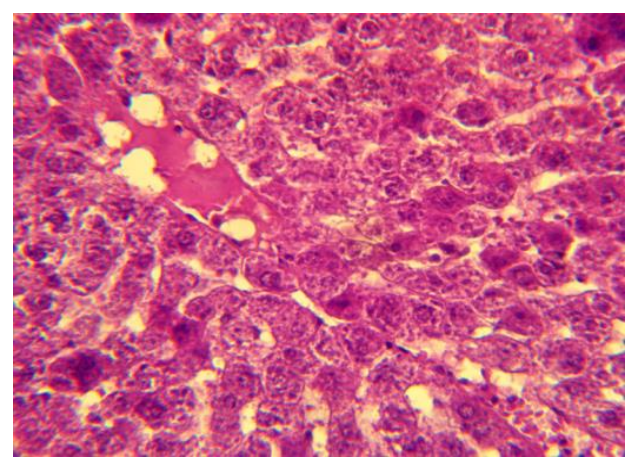

b

Figure 4. The histologic specimen of a rat liver at ETH under amaranth oil application in dose of $300 \mathrm{mg} / \mathrm{kg}$. Colorated with hematoxylin-eosine. Augmentation: $\mathrm{a}-\times 10 ; \mathrm{b}-\times 40$.

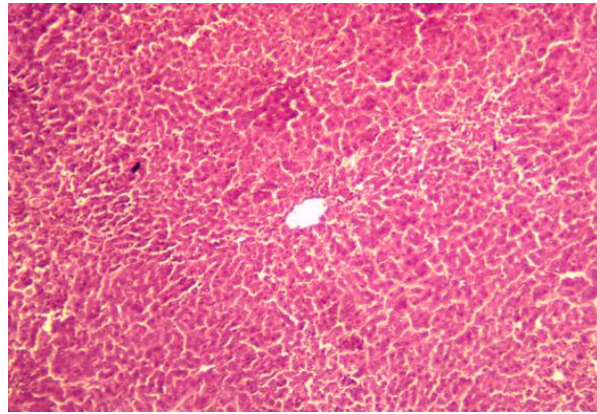

a

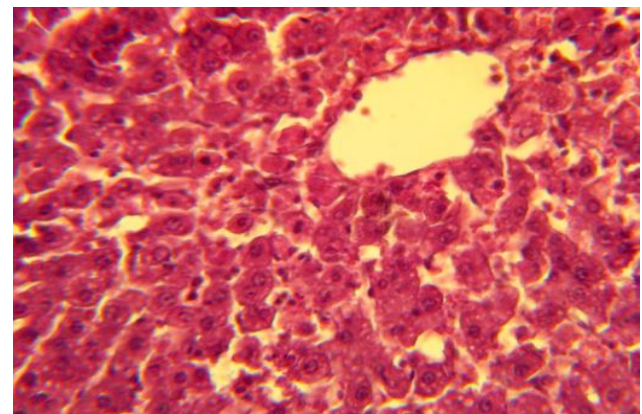

b

Figure 5. The histologic specimen of a rat liver at ETH under amaranth oil application in dose of $600 \mathrm{mg} / \mathrm{kg}$. Colorated with hematoxylin-eosine. Augmentation: $\mathrm{a}-10 ; \mathrm{b}-\times 40$.

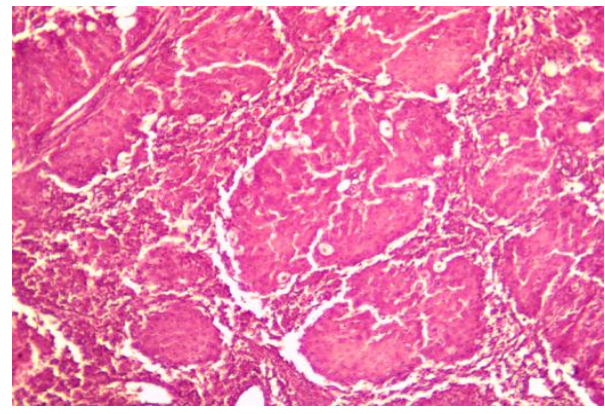

a

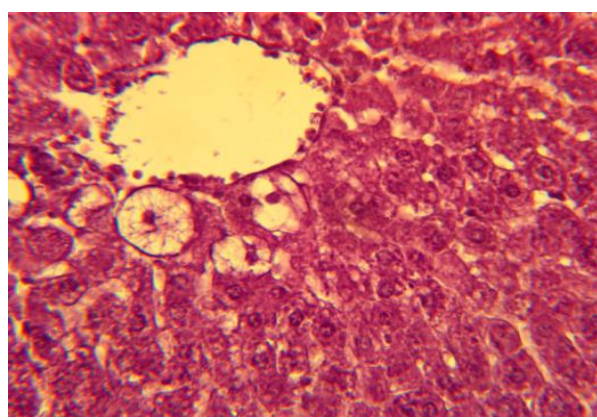

$\mathrm{c}$

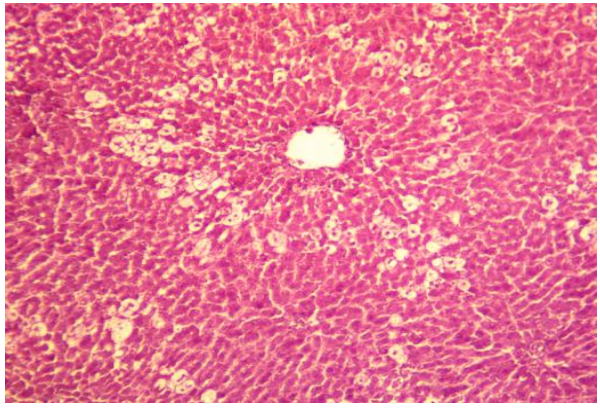

$\mathrm{b}$

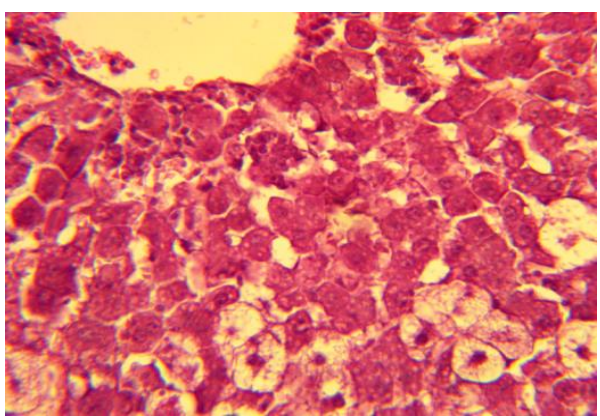

d

Figure 6. The histologic specimen of a rat liver at ETH and amaranth oil application in dose of $1200 \mathrm{mg} / \mathrm{kg}$. Colorated with hematoxylin-eosine. Augmentation: a, b - × 10; c, d - × 40 . 
In the group of the animals preliminary treated with an intragastric introduction of amaranth oil in a dose of $1200 \mathrm{mg} / \mathrm{kg}$, morphological loss of the liver parenchyma girder structure and intensive de-condensation and growth of interlobular connective tissue around the liver portal tracts (Figure 6 a, b) were observed. Thus, the architectonics of hepatic lobules was of the norm. The karyolysis and karyopyknosis phenomena and presence of cirrhotic fields were found. Both the centrolobular hepatocytes and peripheric cells (Figure 6 , b-d) were damaged. This can testify to the dose-dependent effect of amaranth oil application.

\section{DISCUSSION}

Along with the aforementioned considerations, it is worth noting the effects of xenobiotics on the liver. Xenobiotics influence the activity of the monooxygenase enzyme system, whose key point is the family of cytochromes P450, which carry out a catabolism of endogenous biologically active substances and xenobiotics. Depression of P-450 complicates pharmacotherapy essentially and also leads to ekzo - an endotoxin resistance reduction and dysfunction of humoral regulatory mechanisms [9]. Now the drugs boosting the liver antitoxic function and interfering inactivation of P-450 cytochromes are estimated as used widely on liver toxic lesions [1]. Using the hexenalum sleep model, we have reliably proved ability of amaranth oil to decrease the barbiturates-invoked narcotic sleep duration. The changes established argue to presence of amaranth oil's antitoxic activity and most probably characterize its ability to be the hepatocyte microsomal fermentation inducer of the cytochrome P450 system.

Based on the results of the in vitro experiments, it is possible to come to the conclusion that CT invokes damage of a cytoplasmic membrane of the basic population of erythrocytes (at the specified way and introduction dose). It can be bound to augmentation of oxidative processes in a cell's membrane. Preliminary Essentiale and amaranth oil introduction promotes a weakening of the CT damaging activity, which is probably due to the antioxidant properties of these pharmacological active substances. This is consistent with the observation that the phenomenon is realized due to the increasing of membranes' permeability threshold for hydrogen ions compared separate CT application.

On the animals' survival rate model, it is posited that the preliminary introduction of amaranth oil protects an organism against hypoxia invoked by L-thyroxin introduction in doses of 5,10 , and $20 \mathrm{mkg}$, which probably leads to boosting L-thyroxin influence reduction on thyroid gland function.

Amaranth oil hepatoprotective activity is confirmed by the results of biochemical and morphological examinations. This study implicates amaranth oil's preventive appointment in reducing the damage of CT in liver tissue. This effect was especially observed in a dose of $300 \mathrm{mg} / \mathrm{kg}$, which is proved both by normalization of hepatic fermentation-marker indexes and morphological examinations. Effects of oil application in doses of $600 \mathrm{mg} / \mathrm{kg}$ and $1200 \mathrm{mg} / \mathrm{kg}$ testify to a dose-dependent effect developed as a reduction of protective action on the background of regenerative processes in a liver that is expressed by displacement of CT toxic activity on peripheric cells.

\section{CONCLUSIONS}

The amaranth oil received acquired by patented pressing technology possessed the expressed antitoxic and anti-oxidant activity. Against a toxic liver lesion, the oil application 
intensifies regenerative processes. However, the dose-dependent character of this process is worth considering.

Competing interests: The authors declare that they have no competing interests.

Authors' contributions: All authors contributed to this work.

\section{REFERENCES}

1. Ajushieva S.C.: Basic group of hepatoprotective drugs. Siberian medical review 2006, 4:10-16.

2. Sergeev P.V., Shimanovsky N.L.: Biochemical pharmacology. Moscow; 2010.

3. Bliznetsova G. N.: Role of free-radical oxidation processes in the mechanism of hepatoprotective activity of amaranth seeds oil. Biomedicine 2006, 2: 105-112.

4. Miroshnichenko L.A., Zoloedov V.I., Kulakova S.N. et al: Influence of a dietetics with use of sunflower-seed oil and an amaranth oil on indexes of immune reactance at sick of a diabetes of type 2. Voprosy pitania 2009, 4: 30-37.

5. Volynkina A.P.: Clinical efficiency of treatment of diabetes of the second type in a combination to arterial hypertensia incorporation in therapy of oils on the basis of an amaranth and sunflower. Thesis of cand. of Medical sciences, Voronezh; 2008.

6. Korensky I.M.: Farmakognostic studying of seeds of various kinds of an amaranth sad. Thesis of cand. of Ph. Sciences, Voronezh; 2012.

7. Miroshnichenko L.A., Zoloedov V.A., Volynkina A.P. et al: Influence of the amaranth and sunflower oils used in dietetics of patients with diabetes of type 2 on indexes of a carbohydrate and lipide exchange. Voprosy pitania 2008, 6: 53-57.

8. Myshkin V. A., Bakirov A.B., Repina E.F.: Hepatotoxic substances and the modern directions of hepatotoxic activity correction. Medical bulletin of Bashkortostan 2011, 6:131-136.

9. Nikitina I.L.: Search and pharmacology of new inducers of monooxygenase system of azol derivatives. Autoref. of thesis of cand. of Medical sciences. Volgograd; 2004.

10. Okovityj S.V., Sukhanov D.S., Romantsov M.G.: Hepatoprotective agents: a current state problem. Therapeutic archive 2012, 2:62-68.

11. Podymova S.D.: Liver desease. Moscow, Medicine 2005.

12. Tuteljan V.A.: Oil application in dietetics of cardiovascular diseases. Voronezh; 2011.

13. Habriev R.U.: The observational (preclinical) studying of new pharmacological substances management. Moscow, Medicine, 2005.

14. Selemenev V. F., Makeev V.F., Korensky I.M., et al: Studying of phospholipid composition of amaranth oil. Materials of the $4^{\text {th }}$ International symposium «New and nonconventional plants and prospects of it use». Moscow, Pushchino; 2001.

15. Somova M. N., Muzalevskaya E.N., Nikolaevsky V.A. et al: The drug-induced lesions of a liver and problems of it pharmacological correction. Observational and clinical pharmacology 2013, 9:38-43.

16. Makeev A.M., Miroshnichenko L.A., Surovtsev I.S. et al: The Mean of oil reception from amaranth seeds: the applicant and patent holder is Voronezh state university № 94044961/13; rep. 22.12.97; published. 27.05.97, Bul. № 15 - 250 p. 